\title{
Feasibility, acceptability and efficacy of a web-based computer-tailored physical activity intervention for pregnant women - the Fit4Two randomised controlled trial
}

\author{
Melanie Hayman ${ }^{1}$, Peter Reaburn ${ }^{1}$, Matthew Browne ${ }^{2}$, Corneel Vandelanotte ${ }^{3^{*}} \mathbb{D}$, Stephanie Alley ${ }^{3}$ and Camille E. Short ${ }^{4}$
}

\begin{abstract}
Background: Physical activity (PA) during pregnancy is associated with a variety of health benefits including a reduced risk of pregnancy related conditions such as pre-eclampsia and pregnancy-induced hypertension and leads to greater control over gestational weight gain. Despite these associated health benefits, very few pregnant women are sufficiently active. In an attempt to increase health outcomes, it is important to explore innovative ways to increase PA among pregnant women. Therefore, the aim of this study was to assess the feasibility, acceptability and efficacy of a four week web-based computer-tailored PA intervention among pregnant women.
\end{abstract}

Methods: Seventy-seven participants were randomised into either: (1) an intervention group that received tailored PA advice and access to a resource library of articles relating to PA during pregnancy; or (2) a standard information group that only received access to the resources library. Objective moderate-to-vigorous physical activity (MVPA) was assessed at baseline and immediately post-intervention. Recruitment, attrition, intervention adherence, and website engagement were assessed. Questions on usability and satisfaction were administered post-intervention.

Results: Feasibility was demonstrated through acceptable recruitment ( 8.5 participants recruited and randomised/ month), and attrition (25\%). Acceptability among intervention group participants was positive with high intervention adherence ( $96 \%$ of 4 modules completed). High website engagement (participants logged in 1.6 times/week although only required to log in once per week), usability (75/100), and satisfaction outcomes were reported in both groups. However, participants in the intervention group viewed significantly more pages on the website $(p<0.05)$, reported that the website felt more personally relevant $(p<0.05)$, and significantly increased their MVPA from baseline to postintervention (mean difference $=35.87 \mathrm{~min}$ ), compared to the control group (mean difference $=9.83 \mathrm{~min})(p<0.05)$, suggesting efficacy.

Conclusions: The delivery of a computer-tailored web-based intervention designed to increase PA in pregnant women is feasible, well accepted and associated with increases in short-term MVPA. Findings suggest the use of computer-tailored information leads to greater website engagement, satisfaction and greater PA levels among pregnant women compared to a generic information only website.

Trial registration: The trial was 'retrospectively registered' with the Australian New Zealand Clinical Trials Registry (ACTRN12614001105639) on 17 $7^{\text {th }}$ October, 2014.

Keywords: Physical activity, Pregnancy, Intervention, Behaviour change, Web-based, Internet, Online

\footnotetext{
* Correspondence: c.vandelanotte@cqu.edu.au

${ }^{3}$ School of Human, Health and Social Sciences, Central Queensland

University, Rockhampton, QLD 4702, Australia

Full list of author information is available at the end of the article
} 


\section{Background}

Participation in physical activity (PA) during pregnancy is associated with a variety of well-documented physical and physiological health benefits for both the mother and child [1]. These include greater control of gestational weight gain, decreased risk of pregnancy-related complications, such as preeclampsia and hypertension [1]. Despite these benefits, less than 35\% of Australian pregnant women appear sufficiently active $[2,3]$ in accordance with exercise during pregnancy guidelines [4].

PA during pregnancy is linked to a variety of unique barriers experienced during pregnancy [5]. These include barriers such as increased fatigue and tiredness and physical discomfort, lack of time, motivation and/or social support, and neighbourhood or environmental barriers such as bad weather or poorly maintained walking paths [5]. To assist pregnant women overcome these barriers, PA interventions using a variety of strategies have been implemented, including counselling, exercise and educational interventions [6,7]. Most of these PA interventions have traditionally included face-to-face behaviour change programs conducted in a primary care environment by exercise specialists and/or health professionals such as medical practitioners [6, 7]. However, such face-to-face behaviour change programs can be time consuming, expensive and limited in reach $[8,9]$. Online interventions, especially those that employ computer-tailoring, present as an alternative intervention delivery mode to traditional face-to-face interventions; especially given that online interventions have been found to be cost effective, sustainable and wide reaching $[10,11]$.

Computer-tailoring automatically generates personalised feedback and advice based on participants' responses to a series of online questions. While web-based, computertailored interventions have been shown to be effective at increasing PA among other populations, [11] their feasibility, acceptability and efficacy have not been examined among pregnant women. Thus, the purpose of this study was to test the feasibility, acceptability and efficacy of a computer-tailored web-based intervention (Fit4Two) designed to promote PA among pregnant women.

\section{Methods}

This study was a randomised controlled, two-arm, fourweek behaviour change trial with an immediate follow-up, conducted in Rockhampton, Queensland from October 2014 to June 2015. Ethics approval was obtained from Central Queensland University Human Research Ethics Committee (H14/02-031). The protocol was registered with the Australian New Zealand Clinical Trials Registry (ACTRN12614001105639). The reporting and conduct adheres to the Consolidating Standards of Reporting Clinical Trials (CONSORT) guidelines [12].
To be eligible, participants were required to be proficient in English, 18+ years, have a gestational age of 10-20 weeks (ensuring all participants completed the intervention in their second trimester for consistency), and considered healthy and free of any medical and/or obstetric contraindications to participate in PA. To ascertain contraindications, potential participants were required to complete a modified online version of both the Physical Activity Readiness Medical Examination for Pregnancy (PARmed-X for pregnancy) [13] and the Physical Activity Readiness Questionnaire [14]. If participants answered 'yes' to any of the screening questions, they were asked to seek medical approval to participate in the study.

Recruitment involved the dissemination of study information by medical practitioners, such as general practitioners and obstetricians, private and public hospital staff, and free and paid promotion of the study via social media. For all methods, a brief study overview was provided including information on the randomisation process. Following baseline assessment, participants were required to collect a GeneActiv original accelerometer (ActiveInsights, United Kingdom) for which content validity and test-retest reliability has previously been established in pregnant women, [15] from the study site. Participants were instructed to wear the accelerometer on their non-dominate wrist for seven days. Participants were also provided with an A4 instruction sheet including what should happen if the device stopped working, and general care instructions. Data was collected at $100 \mathrm{~Hz}$, with minimum wear time criteria consisting of $>4$ days, $>10$ waking hours/day and including two weekend days. Once objective baseline accelerometer data was successfully collected, participants were then automatically randomised to either the intervention or control group via the study website using a computergenerated block randomisations sequence (with block sizes of four) on a 1:1 ratio. All project team members were blinded to this process.

Participants assigned to the intervention group were given full access to the Fit4Two website. The development of the website content was guided by the Social Cognitive Theory (SCT) given that self-efficacy is a central determinant of the SCT theory, and increasing self-efficacy is recognised as one of the most important determinants of physical activity among pregnant women [16]. The intervention consisted of four weekly modules based on Social Cognitive Theory (SCT) [17] including: (1) information on how to set SMART (specific, measurable, achievable, realistic and timely) goals and develop action plans; (2) overcoming barriers such as environment or lack of time and/or motivation; (3) developing social support networks including work colleagues, family and friends; and (4) PA reinforcement 
such as identifying the benefits associated with meeting the guidelines, all of which have been previously identified as significant constructs to increasing PA among pregnant women $[6,16]$. In addition to the weekly SCT module, participants were also provided with access to a weekly action planning tool, which guided participants in setting a detailed plan for their PA including when they would exercise, who they might exercise with, where the exercise would take place, and what barrier/s might come up, and how they would overcome them over the coming week. Please refer to Table 1 for the operationalisation of the SCT constructs relevant to the Fit4Two study. Figures 1 and 2 show the look and feel of the intervention website.

Upon commencing the intervention, participants were asked a series of questions based on their PA behaviours [18] over the previous seven days, and the weekly SCT constructs (goal setting and action planning, social support, perceived barriers and PA reinforcement). Participants were then provided with immediate computer-tailored feedback messages based on their responses to the PA behaviour and SCT construct questions. For example, if a participant answered that her friends and work colleagues were the ones that provided her with social support to be physically active during her pregnancy, the tailored feedback addressed this. The website also included a resources library providing upto-date, evidence-based advice on current exercise during pregnancy guidelines, aerobic and resistancebased exercise recommendations, safety considerations to exercise during pregnancy, and general advice for active living during pregnancy. Participants assigned to the minimum intervention control group only had access to the resources library for the four-week intervention phase. Upon completion of the intervention phase, participants in the control group were then given unlimited access to the website.

Feasibility was assessed using recruitment, and attrition data. Acceptability was measured through intervention adherence, website engagement, website usability and satisfaction items relating to website quality, relevance and usefulness. Specifically, intervention adherence was measured by number of modules and goal setting/action planning tools that were completed. Website engagement totalled the number of site sessions (log-ins), page views and time spent (minutes) on the website from baseline to four week follow-up using Google Analytics [19]. Website usability was measured using the widely accepted and reliable 10-item System Usability Scale (SUS) [20]. All items were assessed on a five-point Likert scale with response items ranging from 'strongly agree' to 'strongly disagree'. Reverse coding was used to adjust scores for negativelyframed items before participants' response scores were added together for all 10 items and then multiplied by 2.5 .
This allowed for the original scores ranging from 0 to 40 to be converted to a score of 1-100. Based on previous research, a score above 68 on the SUS scale indicates 'above average usability' [20]. Finally, participant's perceptions of the website in terms of how much they would like to continue to use it, and how credible, interesting, easy to understand, and personally relevant they found the website were assessed using five items from previous tailoring studies on a five-point Likert scale (1 - strongly disagree -5 strongly agree) [21, 22]. For example, participants were asked to rate their level of agreement that 'the content was personally relevant to me' and 'I would like to continue using the Fit4Two website throughout the remainder of my pregnancy'. Two open-ended questions were also used to ask participants; (1) what they liked and/or disliked about the website and; (2) how they believe the website could be improved.

Efficacy was determined based on a $2 \times 2$ group $\mathrm{X}$ time interaction model describing differences in moderatevigorous physical activity (MVPA), controlling for baseline differences. The GeneActiv accelerometer data was used to assess MVPA objectively at baseline (seven days prior to randomisation) and follow-up (seven days after completing the Fit4Two study). At the end of each collection period, the raw accelerometer output data was uploaded into the GeneActiv post-processing software (GeneActiv, version 2.2, Activinsights Ltd) and converted into $60 \mathrm{~s}$ epoch files. The epoch files were then processed using the GGIR script in the $R$ environment (http://cran.r-project.org) [23] to produce a series of standardised accelerometery outcome variables. Finally, validated acceleration magnitude cut points were used to classify activity into light, moderate and vigorous intensities [24].

Chi-square and analyses of variance were performed using SPSS Version 20 (IBM Corp, NY) to determine between group differences for all measures of participants who completed the study, with the exception of MVPA [25]. The distribution of MVPA residuals violated normal assumptions due to excessive zeroes (33\% of all observations) and over-dispersion (positive skew). Whilst specialised generalised distributions are available to handle this, these are not implemented for repeated measures/linear mixed effects models required to handle the repeated measures. Therefore, for the purpose of hypothesis testing, the over-dispersion was dealt with by transforming the response via $\log (\mathrm{MVPA}+1)$. The zero-inflation was handled with recourse to the semiparametric bootstrap (5000 replicates) for robust calculation of confidence intervals. The model included main effects for time (pre, post) and group (intervention, control), with the hypothesis addressed by a group $\mathrm{X}$ time interaction term. Statistical significance was set at $P<0.05$ (two-tailed, corresponding to 0.025 one-tailed). 
Table 1 Operationalisation of the SCT Constructs relevant to this study

\begin{tabular}{|c|c|c|}
\hline $\begin{array}{l}\text { Module } 1 \\
\text { Strategy }\end{array}$ & SCT construct & Tailoring variables \\
\hline Advice for meeting the PA guidelines & Self-efficacy & $\begin{array}{l}\text { PA status } \\
\text { PA level prior to pregnancy }\end{array}$ \\
\hline $\begin{array}{l}\text { Information about the beneficial outcomes } \\
\text { of PA, exercise during pregnancy guidelines, } \\
\text { resistance-based exercise guidelines and } \\
\text { stretching }\end{array}$ & Outcome expectations & $\begin{array}{l}\text { Outcome expectancies } \\
\text { (outcomes valued by individual) }\end{array}$ \\
\hline Advice and information on BMI classifications & $\begin{array}{l}\text { Self-efficacy } \\
\text { Behavioural capability } \\
\text { Outcome expectations }\end{array}$ & $\begin{array}{l}\text { Behavioural capability } \\
\text { Outcome expectancies (outcomes valued by } \\
\text { individual) }\end{array}$ \\
\hline Advice on exercise intensity & Self-efficacy & $\begin{array}{l}\text { PA status } \\
\text { Current PA level }\end{array}$ \\
\hline Advice on exercising safely & $\begin{array}{l}\text { Self-efficacy } \\
\text { Behavioural capability } \\
\text { Outcome expectations }\end{array}$ & $\begin{array}{l}\text { Behavioural capability } \\
\text { Outcome expectancies } \\
\text { (outcomes valued by individual) }\end{array}$ \\
\hline Action planning & $\begin{array}{l}\text { Self-efficacy } \\
\text { Self-control and performance }\end{array}$ & $\begin{array}{l}\text { PA status } \\
\text { PA preference }\end{array}$ \\
\hline \multicolumn{3}{|l|}{ Module 2} \\
\hline Feedback on PA performance & $\begin{array}{l}\text { Self-efficacy } \\
\text { Self-control and performance } \\
\text { Reinforcement }\end{array}$ & $\begin{array}{l}\text { PA status } \\
\text { PA progress since M1 }\end{array}$ \\
\hline $\begin{array}{l}\text { Advice on overcoming possible barriers } \\
\text { to exercise during pregnancy }\end{array}$ & $\begin{array}{l}\text { Environment } \\
\text { Self-efficacy } \\
\text { Self-control and performance }\end{array}$ & $\begin{array}{l}\text { Self-discipline } \\
\text { Time } \\
\text { Health/illness } \\
\text { Tired and exhausted } \\
\text { Motivation } \\
\text { Social Support } \\
\text { Knowledge } \\
\text { Environment }\end{array}$ \\
\hline Action planning & $\begin{array}{l}\text { Self-efficacy } \\
\text { Self-control and performance }\end{array}$ & $\begin{array}{l}\text { Goal setting behaviour after M1 } \\
\text { PA status }\end{array}$ \\
\hline \multicolumn{3}{|l|}{ Module 3} \\
\hline Strategy & SCT construct & Tailoring variables \\
\hline Feedback on PA performance & $\begin{array}{l}\text { Self-efficacy } \\
\text { Self-control and performance } \\
\text { Reinforcement }\end{array}$ & $\begin{array}{l}\text { PA status } \\
\text { PA progress since } M 1 \text { and } M 2\end{array}$ \\
\hline $\begin{array}{l}\text { Advice and tips on increasing social support to } \\
\text { exercise during pregnancy }\end{array}$ & $\begin{array}{l}\text { Environment } \\
\text { Self-efficacy } \\
\text { Self-control and performance }\end{array}$ & Partner Family and Friends Work colleagues \\
\hline Action planning & $\begin{array}{l}\text { Self-efficacy } \\
\text { Self-control and performance }\end{array}$ & $\begin{array}{l}\text { Goal setting behaviour after } \mathrm{M} 1 \text { and } \mathrm{M} 2 \\
\text { PA status }\end{array}$ \\
\hline \multicolumn{3}{|l|}{ Module 4} \\
\hline Feedback on PA performance & $\begin{array}{l}\text { Self-efficacy } \\
\text { Self-control and performance } \\
\text { Reinforcement }\end{array}$ & $\begin{array}{l}\text { PA status } \\
\text { PA progress since } \mathrm{M} 1, \mathrm{M} 2 \text { and } \mathrm{M} 3\end{array}$ \\
\hline $\begin{array}{l}\text { Reminder on Exercise during pregnancy } \\
\text { guidelines and recommendations }\end{array}$ & $\begin{array}{l}\text { Self-efficacy } \\
\text { Self-control and performance } \\
\text { Reinforcement }\end{array}$ & $\begin{array}{l}\text { PA status } \\
\text { PA progress since } \mathrm{M} 1, \mathrm{M} 2 \text { and } \mathrm{M} 3\end{array}$ \\
\hline Action planning & $\begin{array}{l}\text { Self-efficacy } \\
\text { Self-control and performance }\end{array}$ & $\begin{array}{l}\text { Goal setting behaviour after M1, M2 and M3 } \\
\text { PA status }\end{array}$ \\
\hline
\end{tabular}

\section{Results}

A total of 425 'guests' visited the Fit4Two website over the nine-month recruitment period, with 149 women expressing interest in the study and screened for eligibility.
Seventy-seven eligible participants provided informed consent by agreeing to the study terms and conditions listed on the Fit4Two website, and by choosing to continue in the study to complete the baseline survey, and wear an 

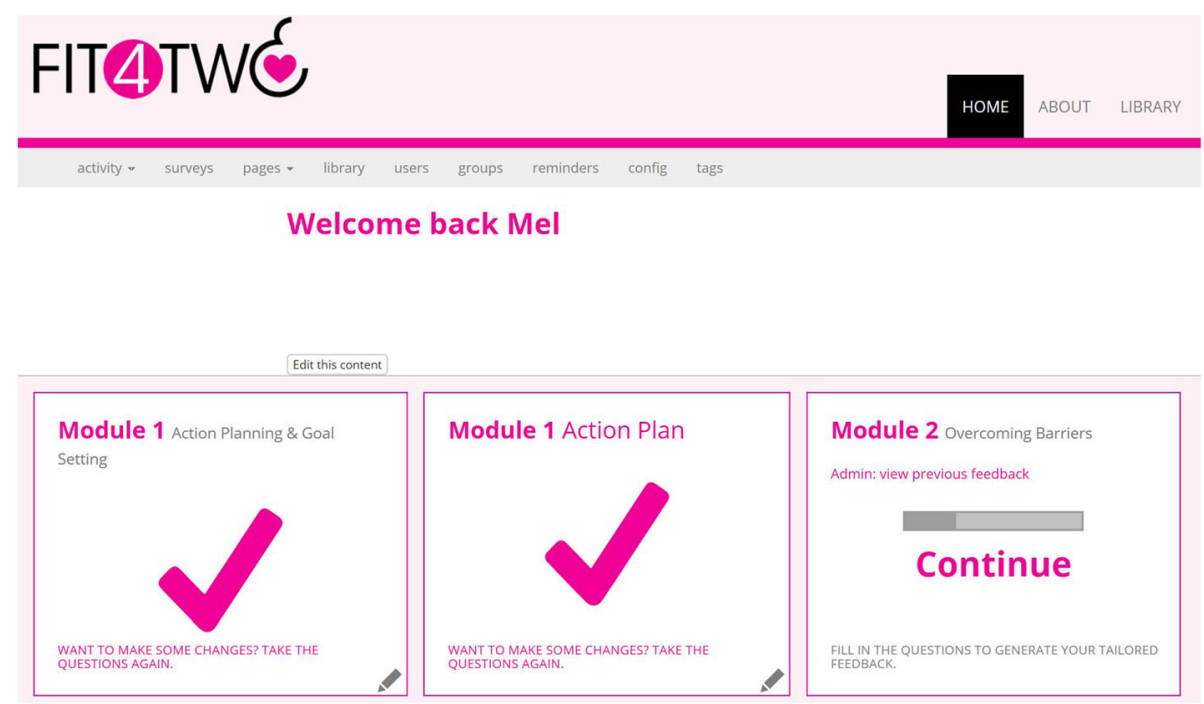

Fig. 1 Fit4Two Website Homepage

accelerometer in accordance with the study's adherence guidelines. These participants were then randomised to either the control group $(n=38)$ or intervention group $(n=$ 39 ). The main reasons for ineligibility were geographical location or gestational age being greater than 20 weeks. Of these 77 randomised participants, 18\% were recruited from marketing materials displayed in doctor/hospital/obstetrician clinics, 9\% were recruited via family and/or friends, and $59 \%$ via media outlets (Facebook $47 \%$, community news $3 \%$, other $9 \%$ ). There was no significant difference in attrition rates between groups. Twenty participants dropped out of the study including 8 from the control group (80\% retention) and 12 from the intervention group (70\% retention). The flow of participants through the study is displayed in Fig. 3.
Baseline characteristics for all participants are shown in Table 2. There were no significant demographic differences between groups. Compared to available national data, participants were found to be representative of the target population [26] for age (mean 29 years), BMI (mean $26 \mathrm{~kg} / \mathrm{m}^{2}$ ), combined household income $(62 \%$ earned less than $\$ 100,000$ per year), and highest level of education (51\% completed a university degree).

Feasibility, acceptability and efficacy outcomes are shown in Table 3. Of the participants who completed the study and were allocated to the intervention group ( $n=27)$, 96\% completed all four of the weekly SCTbased modules. Adherence to the Goal Setting/Action Planning tool was also positive (72\%), with all participants completing Action Plans 1 and 2, 59\% $(n=16)$

\section{FIT४TWर्ध}

HOME ABOUT LIBRARY

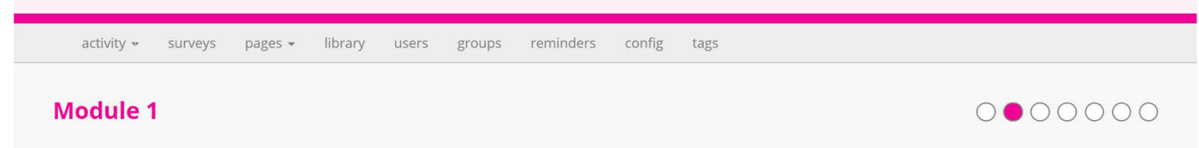

Your Aerobic Activity Feedback

You reported not participating in any aerobic activity before you received your personalised physical activity advice from your practitioner. However, we can see that you are now participating enough aerobic activity to be meeting the exercise during pregnancy guidelines. Wow - what a fantastic turn around!

You are now participating in 400 minutes accumulated across 6 days.

We understand that pregnancy can be an extremely tough, exhausting and challenging time. The great news is that you have made the first step in a very positive direction, so now it's a matter of keeping up the great work!

We are hopeful that after you complete this module that is based on setting SMART goals and developing action plans, and in conjunction with your personalised physical activity plan that you already have, that you can continue your fantastic aerobic exercise activity.

Congratulations again on making such a positive first step, as it is ALWAYS the hardest!

Fig. 2 Example of Fit4Two aerobic feedback 


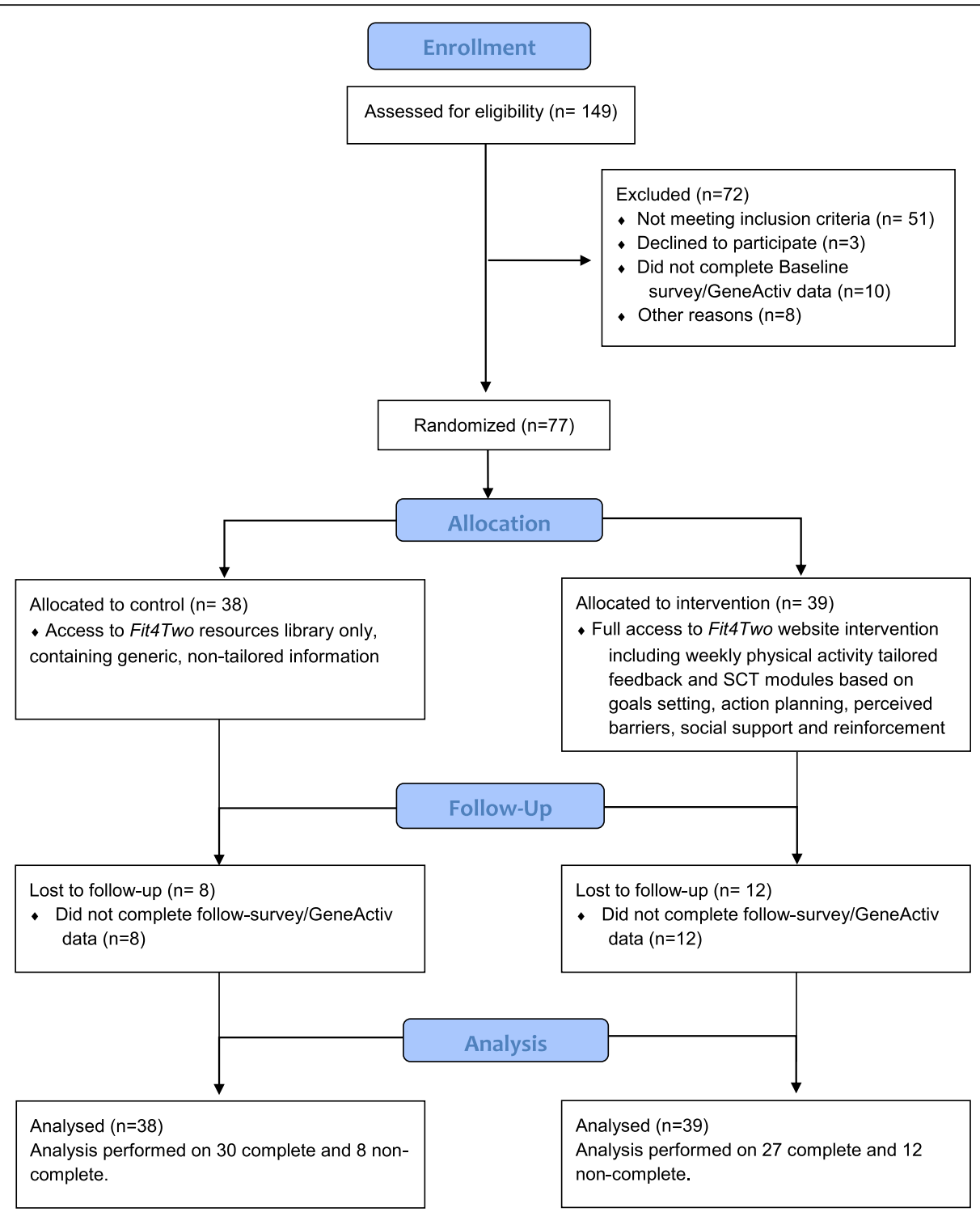

Fig. 3 CONSORT Flow Chart of Participants through the Fit4Two Study

completing Action Plan 3 and 30\% $(n=8)$ completing Action Plan 4.

Website engagement was highest in the intervention group, with participants in this group recording more sessions (log-ins), spending longer on the website and viewing significantly more pages $(p<0.05)$, than those in the control group. All participants scored the usability of the website 'above average' with a mean score of 75/100 [20]. Participant satisfaction was positive with the majority of participants either 'strongly agreeing' or 'agreeing' that website as credible, the content was easy to understand, and that they would like to have continued to use the website throughout the remainder of their pregnancy. No significant between-group differences were observed for any measure
Table 2 Demographic characteristics of Fit4Two participants

\begin{tabular}{|c|c|c|c|c|c|c|}
\hline \multirow[t]{2}{*}{ Variable } & \multicolumn{2}{|c|}{$\begin{array}{l}\text { Intervention } \\
(n=39)\end{array}$} & \multicolumn{2}{|c|}{$\begin{array}{l}\text { Control } \\
(n=38)\end{array}$} & \multicolumn{2}{|c|}{$\begin{array}{l}\text { Total } \\
(n=77)\end{array}$} \\
\hline & $\bar{n}$ & $\%$ & $\mathrm{n}$ & $\%$ & $\bar{n}$ & $\%$ \\
\hline Married, de facto & 34 & 87 & 34 & 89 & 68 & 88 \\
\hline Completed university & 19 & 49 & 20 & 53 & 39 & 51 \\
\hline $\begin{array}{l}\text { Combined Household Income } \\
(\$ 100,000-\$ 150,000 \text { per year })\end{array}$ & 12 & 31 & 17 & 45 & 29 & 38 \\
\hline Full-time employed & 17 & 44 & 21 & 55 & 38 & 49 \\
\hline Born in Australia & 31 & 79 & 37 & 97 & 68 & 88 \\
\hline One other child at home & 21 & 54 & 15 & 39 & 37 & 48 \\
\hline Have been pregnant before & 27 & 69 & 23 & 60 & 50 & 65 \\
\hline Private Health Care & 28 & 72 & 26 & 68 & 54 & 70 \\
\hline
\end{tabular}


Table 3 Feasibility, acceptability and efficacy of Fit4Two participants

\begin{tabular}{|c|c|c|c|c|}
\hline \multirow[t]{2}{*}{ Measure } & \multicolumn{2}{|c|}{$\begin{array}{l}\text { Intervention } \\
(n=27)\end{array}$} & \multicolumn{2}{|c|}{$\begin{array}{l}\text { Control } \\
(n=30)\end{array}$} \\
\hline & $\mathrm{N}$ & $\%$ & $\mathrm{~N}$ & $\%$ \\
\hline \multicolumn{5}{|l|}{ Acceptability measures } \\
\hline \multicolumn{5}{|l|}{ Adherence } \\
\hline Module 1 & 27 & 100 & \multicolumn{2}{|c|}{ N/A } \\
\hline Module 2 & 27 & 100 & \multicolumn{2}{|c|}{ N/A } \\
\hline Module 3 & 26 & 96 & \multicolumn{2}{|c|}{ N/A } \\
\hline Module 4 & 27 & 100 & \multicolumn{2}{|c|}{$\mathrm{N} / \mathrm{A}$} \\
\hline Action Plan 1 & 27 & 100 & \multicolumn{2}{|c|}{ N/A } \\
\hline Action Plan 2 & 27 & 100 & \multicolumn{2}{|c|}{ N/A } \\
\hline Action Plan 3 & 16 & 60 & \multicolumn{2}{|c|}{ N/A } \\
\hline Action Plan 4 & 8 & 30 & \multicolumn{2}{|c|}{$\mathrm{N} / \mathrm{A}$} \\
\hline \multicolumn{5}{|l|}{ Website engagement } \\
\hline Website session (log ins) & \multicolumn{2}{|l|}{7} & \multicolumn{2}{|l|}{6} \\
\hline Website page views & \multicolumn{2}{|l|}{$144^{*}$} & \multicolumn{2}{|c|}{110} \\
\hline $\begin{array}{l}\text { Average time spent on website } \\
\text { (mins/session) }\end{array}$ & \multicolumn{2}{|l|}{12} & \multicolumn{2}{|l|}{11} \\
\hline \multicolumn{5}{|l|}{ Usability } \\
\hline SUS Scale (score out of 100) & \multicolumn{2}{|l|}{75} & \multicolumn{2}{|l|}{75} \\
\hline \multicolumn{5}{|l|}{ Satisfaction data } \\
\hline Found the website credible & 19 & $71 \%$ & 23 & $77 \%$ \\
\hline Found the website interesting & 21 & $78 \%$ & 21 & $70 \%$ \\
\hline Content easy to understand & 23 & $85 \%$ & 23 & $80 \%$ \\
\hline Content was personally relevant to me & $19^{*}$ & $71 \%$ & 18 & $60 \%$ \\
\hline $\begin{array}{l}\text { Would like to continue using the website } \\
\text { throughout pregnancy }\end{array}$ & 21 & $78 \%$ & 22 & $74 \%$ \\
\hline \multicolumn{5}{|c|}{ Efficacy measures (objective pre-post MVPA mean change scores) } \\
\hline Objective & \multicolumn{2}{|c|}{$\begin{array}{l}+36 \text { min } \\
\text { per week* }\end{array}$} & \multicolumn{2}{|c|}{$\begin{array}{l}\text { +9 min } \\
\text { per week }\end{array}$} \\
\hline
\end{tabular}

of acceptability with the exception of perceived content relevance, where participants in the intervention group felt the website content was significantly more relevant to them personally than those in the control group $(p=0.024)$. Whilst many participants said 'they would not change a thing, some participants suggested that the inclusion of actual exercise programs would have benefited the program.

Table 3 shows that at follow-up, participants in the intervention group were found to have increased their MVPA (mean increase $36 \mathrm{~min} /$ week) more than those in the control group (mean increase $9 \mathrm{~min} /$ week). This group $\mathrm{x}$ time interaction was significant when MVPA was modelled on the log scale using bootstrapped confidence intervals, $\beta_{\text {group } X \text { time }}=1.31,95 \%$ CI $[0.175$, 2.484 ], $p=0.0126$. There were no adverse events, or unintended harm reported from participants in this study.

\section{Discussion}

The present study is the first study to explore the feasibility, acceptability and efficacy of a web-based computer-tailored intervention aimed at increasing PA among pregnant women. The feasibility of the Fit4Two program was demonstrated in terms of successful recruitment and attrition throughout the screening process with no participants dropping out between eligibility and randomisation. Acceptability was also established, with the majority of participants rating the website positively and reporting above average usability scores. Almost all participants allocated to the intervention group engaged with the tailored modules and action plans as intended. Finally, there was evidence in favour of the Fit4Two program in terms of efficacy, with those allocated to the intervention group showing a significant increase in MVPA compared to the control group.

The feasibility outcomes in this study are favourable compared to other studies [27-29]. For example, the present study recruited and randomised an average of 9 participants per month from targeted marketing in a regional Australian town with a population of approximately 65,000 people [30]. In comparison, a recent study examining the feasibility and efficacy of a PA mobile health intervention among Australian pregnant women from a metropolitan area of nearly 600,000 people, [27] recruited and randomised 5.6 participants per month [27]. Almost half (47\%) of the participants within this study were recruited via the social media platform, Facebook. In this study, paid advertisements that included the Fit4Two study logo, and targeted central Queensland pregnant women wanting to know more about physical activity during pregnancy were used, and found to be a very effective recruitment tool. This is not surprising however given the fact that pregnant women are already reported to be utilising the web to source, and seek out, pregnancy related information. Specifically, the emergence of information technology sees over 93\% of pregnant women using the internet to source additional information about their pregnancy with $83 \%$ using eHealth information to assist in decision-making during their pregnancy [31, 32].

The attrition rate in the present study (26\%) is considered acceptable for PA web-based interventions undertaken in non-pregnant populations, [33] and also fell well within the lower range of attrition rates reported for PA interventions among pregnant women (0-43\%) [6]. Web-based interventions are commonly associated with larger attrition among participants (up to $80 \%$ ), more so among participants allocated to intervention/treatment groups compared to those of a control group [30]. In the present study, more participant drop-outs were observed in the intervention group (30\%) compared to the control group (21\%). This finding is not uncommon in interventions, [34] given the greater burden placed on intervention participants [34].

Participant acceptability in terms of adherence, website engagement, usability and process evaluation data in our 
study was very high compared to other web-based studies among pregnant women [27-29]. All but one participant completed all four of the weekly SCT modules. A total of 78/108 (72\%) goal setting/action planning tasks were also completed. This finding is positive when compared to previous studies that have used goal setting and action planning tools in both pregnant women [27] and other populations [34]. However, in line with other studies, the use of the action plan tool did decline overtime. There may be a number of explanations for this observation. For example, some participants may not have felt that they needed to continue to set goals or develop action plans after the first two weeks of the intervention because they were successfully increasing their PA. Alternatively, participants may have felt that setting goals and developing action plans on a weekly basis was too demanding. Irrespective of the reasoning behind this decline, it is important that participants are aware of the positive relationship between setting goals, developing action plans, and overcoming barriers to PA $[6,35]$.

Participants in this study logged in an average of 1.63 times per week. This is a positive finding given that participants in the intervention group were only required to log-in once a week, and participants in the control were only required to $\log$ in once throughout the entire intervention period. This figure is higher than studies previously undertaken in pregnant women [27]. For example, in a recent web-based intervention aimed at increasing PA among pregnant women, 64\% (29/45) of participants were reported as having 'no engagement' or 'low engagement' with the website tools, characterised by number of log-ins and interaction with the website content [27]. Possible explanations for the differing findings may be that the Fit4Two website included activities designed to help bring about positive behavioural changes, or that participants received computer-tailored feedback that was immediate, personalised, and based on their reported PA behaviours and perceived barriers to PA [27]. Alternatively, participants found the resources library section of the website useful and visited it frequently.

Participant satisfaction data was positive. However, participants in the intervention group reported that the content of the website was significantly more relevant to them than the participants in the control group. Interventions utilising computer-tailored messaging have previously been shown to be more effective at increasing PA (in other populations) than generic, non-tailored messaging, and this is believed to be owing to increased personal relevance $[10,11,33]$. Thus, the use of computer-tailoring in PA interventions among pregnant women is recommended to increase participant acceptability and efficacy. However, participants reported that the provision of specific exercise programs would have further enhanced the Fit4Two website. This request is supported by the literature in that some women still perceive exercise during pregnancy as somewhat 'unsafe' and are 'unsure' as to what exercise they can and cannot do $[35,36]$. The reason for not providing exercise programs as a part of the Fit4Two program was because the research team did not believe the provision of generic programs would be safe for all participants, thus not taking into consideration their health status, physiological differences and possible contraindications to physical activity. However, future interventions might look to involve an accredited exercise physiologist (AEP) or other appropriately skilled professional to provide this service. Alternatively, the intervention could incorporate a referral tool that helps to link pregnant women with local AEPs within their area.

Finally, the efficacy of the Fit4Two project was confirmed with the intervention group significantly increasing their MVPA in comparison to the control group. This increase in MVPA is most likely a result of the personalised and relevant computer-tailored feedback that included appropriate behaviour change techniques (BCTs), identified by the use of the SCT theoretical framework [12, 29]. The benefit of using theories such as the SCT is that they help identify key determinants that assist in the selection of appropriate behaviour change techniques to overcoming the determinants of PA in specific cohorts, thus increasing the personal relevance of the intervention [16]. In the present study, participants in the intervention group were taught how to set goals and develop action plans, overcome perceived barriers to PA, and how to develop social support networks. Each of these BCTs has previously been identified as major facilitators to increasing PA among pregnant women $[6,7,16]$.

Taken together, the findings in this study suggest that the Fit4Two program is feasible, acceptable and efficacious. The use of the SCT theoretical framework used to guide the development and design of the program, and the incorporation of computer-tailored messaging are two recognisable strengths of this study. Additional strengths of this study include the use of objectively measured MVPA and website engagement. A limitation to this study was that the only follow-up occurred immediately after the completion of the intervention. It is recommended that future studies also consider an additional follow-up time point to access the long-term efficacy of the intervention. Based on the positive findings of the present study, a larger trial of Fit4Two undertaken across a nationally representable sample is warranted.

\section{Conclusions}

The positive feasibility, acceptability and efficacy findings associated with the present study suggests that the delivery of a web-based computer-tailored intervention 
for pregnant women presents as a promising approach to increasing PA among pregnant women. A larger study undertaken across a nationally representable sample is now recommended.

\section{Abbreviations}

AEP: Accredited exercise physiologist; BCT: Behaviour change theory; MVPA: Moderate-to-vigorous physical activity; PA: Physical activity; SCT: Social cognitive theory

\section{Acknowledgements}

We thank the study participants for their time and willingness to participate in this study. We also thank the participating practices and their staff who also supported this study.

\section{Funding}

This study was supported by funding from the Central Queensland 'Healthy CQ' Grants Scheme. The authors also acknowledge the time and effort contributed by the participants. CS is supported by a National Health and Medical Research Council ECR Fellowship (ID 1090517). CV (ID 100427) is supported by a Future Leader Fellowship from the National Heart Foundation of Australia.

\section{Availability of data and materials}

The dataset used and/or analysed during this current study is available from the corresponding author on reasonable request.

\section{Authors' contributions}

$\mathrm{MH}, \mathrm{CS}, \mathrm{PR}$ and CV conceived the study, participated in its design and coordination. MC, CS, SA and MB performed the analysis. All authors helped to draft the manuscript, read and approved the final manuscript.

\section{Competing interests}

The authors declare that they have no competing interests.

\section{Consent for publication}

Not applicable.

\section{Ethics approval and consent to participate}

Ethics approval was obtained from CQUniversity Human Research Ethics Committee (H14/02-031). Informed consent to participate in the study was obtained from all participants.

\section{Publisher's Note}

Springer Nature remains neutral with regard to jurisdictional claims in published maps and institutional affiliations.

\section{Author details}

'School of Medical and Applied Sciences, Central Queensland University, Rockhampton, QLD 4702, Australia. 'School of Human, Health and Social Sciences, Central Queensland University, Bundaberg, QLD 4670, Australia. ${ }^{3}$ School of Human, Health and Social Sciences, Central Queensland University, Rockhampton, QLD 4702, Australia. ${ }^{4}$ NHMRC ECR Fellow. Freemasons Foundation Centre for Men's Health. Faculty of Health Sciences, The University of Adelaide, Adelaide, SA 5000, Australia.

Received: 5 December 2016 Accepted: 14 March 2017

Published online: 23 March 2017

\section{References}

1. Harrison CL, Brown WJ, Hayman MJ, Moran LJ, Redman LM. The Role of Physical Activity in Preconception, Pregnancy and Postpartum Health. Semin Reprod Med. 2016; 34(2):e28-37.

2. Hayman M, Short $C$, Reaburn P. An investigation into the exercise behaviours of regionally-based Australian pregnant women. J Sci Med Sport. 2016:19(8):664-8.

3. Wilkinson S, Miller $Y$, Watson B. Prevalence of health behaviours in pregnancy at service entry in a Queensland health service district. Aust N Z J Public Health. 2009;33(3):228-33.
4. Hayman M, Ferrar K, Marchese R, Tan J, Brown W: Exercise in pregnancy and the postpartum period. Sports Medicine Australia (SMA) Position Statement (2016). Available online at: www.sma.org. Accessed Sept 2016.

5. Evenson K, Moos M, Carrier K, Siega-Riiz A. Perceived barriers to physical activity among pregnant women. Matern Child Health J. 2009;13:364-75.

6. Currie S, Sinclair M, Murphy M, Madden E, Dunwoody L, Liddle D. Reducing the decline in physical activity during pregnancy: a systematic review of behaviour change interventions. PLoS One. 2013;8(6):e66385.

7. Pearce E, Evenson K, Downs D, Steckler A. Strategies to promote physical activity during pregnancy: a systematic review of intervention evidence. Am J Lifestyle Med. 2013;7(1). doi:10.1177/1559827612446416..

8. Foster C, Hillsdon M, Thorogood M, Kuar A, Wedatilake T. Interventions for promoting physical activity. Cochrane Database Syst Rev. 2005;(Issue 1): CD003180. doi:10.1002/14651858.CD003180.pub2.

9. Noar S, Benac C, Harris M. Does tailoring matter? Meta-analytic review of tailored print health behaviour change interventions. Psychol Bull. 2007; 133(4):673-93.

10. Lustria M, Noar S, Cortese J, Van Stee S, Glueckauf R, Lee J. A meta-analysis of web-delivered tailored health behavior change interventions. J Health Commun. 2013;18(9):1039-69.

11. Wolfenden L, Nathan N, Williams CM. Computer-tailored interventions to facilitate health behavioural change. Br J Sports Med. 2014;49(22):1478-9.

12. Moher D, Hopewell S, Schulz K: CONSORT 2010 explanation and elaboration: updated guidelines for reporting parallel group randomised trials. BMJ. 2010;340(c869). doi:10.1136/bmj.c869.

13. Canadian Society for Exercise Physiology (CSEP). Physical Activity Readiness Medical Examination for Pregnancy [PARmed-X for pregnancy]. 2015. Available online at: http://www.csep.ca. Accessed June 2016.

14. Godin G, Shepard R. Godin leisure-time exercise questionnaire. Med Sci Sports Exerc. 1997;29:36-8.

15. van Hees VT, Renstorm F, Wright A, Gradmark A, Catt M, Chen K, Lof M, Bluck L, Pomeroy J, Wareham N, et al. Estimation of daily energy expenditure in pregnant and non-pregnant owmen using a wrist-worn triaxial accelerometer. PLoS One. 2011;6(7):e22922

16. Gaston A, Cramp A. Exercise during pregnancy: a review of patterns and determinants. J Sci Med Sports Med Aust. 2011:14(4):299-305.

17. Bandura A. Health promotions by social cognitive means. Health Edud Behav. 2004;31(2):143-64

18. Australian Institute of Health and Welfare (AlHW). The Active Australia Survey: A guide and manual for implementation, analysis and reporting. Cat. No. CVD 22. Canberra: AlWH. Available online at: www.aihw.gov.au. Accessed Nov 2015.

19. Esolang A. Google analytics computer software. Available online at: https:// developers.google.com/analytics. Accessed June 2015

20. Bangor A, Kortum P, Miller J. An emperical evaluation of the system usability scale. Int J Human-Computer Interact. 2008:24(6):574-94.

21. Short C, James E, Girgis A, Souza M, Plotnikoff R. Main outcomes of the move more for life trial: a raondomised controlled trial examining the effects of tailoredprint and targeted-print materials for promoting physical activity among posttreatment breast cancner survivors. Psycho-Oncology. 2015;24(7):771-8.

22. Compernolle S, Vandelanotte C, Cardon G, De Bourdeaudhuij I, De Cocker K. Effectiveness of a web-based, computer-tailored, pedometer-based physical activity intervention for adults: a cluster randomized controlled trial. JMIR. 2015;17(2):e38.

23. Van Hees V, Fang Z, Zheo J, Sabia S. GGIR: Raw accelerometer data analysis. 2017. Available online at: https://cran.r-project.org. Accessed Mar 2017.

24. Esliger D, Rowlands AV, Hurst T, Catt M, Murray P, Eston R. Validation of the GENEA accelerometer. Med Sci Sports Exerc. 2011;43(6):1085-93.

25. R Core Team. R: A Language and Environment for Statistical Computing. Vienna: R Foundation for Statistical Computing; 2014. Available online at: http://www.R-project.org/. Accessed July 2015.

26. Mishra G, Loxton D, Anderson A, Hockey R, Powers J, Brown W, Dobson A, Duffy L, Graves A, Harris M, et al. Health and wellbeing of women aged 18 to 23 in 2013 and 1996: Findings from the Australian Longitudinal Study on Women's Health. Australian Report prepared for the Australian Government Department of Health; 2014. Available online at: http://www.alswh.org.au. Accessed Jan 2016.

27. Smith K. The blossom project online: use of a behaviourally-based website to promote physical activity and prevent excessive gestational wieght gain in previoulsy sedentary pregnant women. Graduate Theses and Dissertations. Paper 14051. 2014. Available online at: http//lib.driastateedu/cgi/. Accessed June 2016.

28. Choi J, Lee J, Vittinghoff E, Fukuoka Y. mHealth physical activity intervention: a randomised pilot study in physically inactive pregnant women. Matern Child Health J. 2016;20:1091-101. 
29. Hayes L, Mcparlin C, Kinnunen T, Poston L, Robson S, Bell R. Change in level of physical activity during pregnancy in obese women: findings from the UPBEAT pilot trial. BMC Pregnancy Childbirth. 2015;15(52):1-8.

30. Australian Bureau of Statistics (ABS). Regional Data Summary: Rockhampton (SA3). Available online at: www.stat.abs.gov.au/. Accessed Sept 2015

31. Lagan $B$, Sinclair $M$, Kernohan $W$. Internet use in pregnancy informs women's decidion making: a web-based survey. Birth. 2010;37(2):106-15.

32. McMullan M. Patients using the internet to obtain health information: how this affects the patient-health professional relationship. Patient Educ Couns. 2006;63(1-2):24-8.

33. Davies C, Spence J, Vandelanotte C, Caperchione C, Mummery K. Metaanalysis of internet-delivered interventions to increase physical activity levels. Int J Behav Nutr Phys Act. 2012;9(52). doi:10.1186/1479-5868-9-52.

34. Evenson K, Bradley C. Beliefs about exercise and physical activity among pregnant women. Patient Educ Couns. 2010;79:124-9.

35. Symons Downs D, Chasan-Taber L, Evenson K, Leiferman J, Yeo S. Physical activity and pregnancy. Res Q Exerc Sport. 2012;83(4):485-502.

36. Prestwich A, Sniehotta F, Whittington C, Dombroski S, Rogers L, Michie S. Does theory influce the effectiveness of health behavior interventions? Meta-analysis. Health Psychol Rev. 2013;33(5):465-74.

Submit your next manuscript to BioMed Central and we will help you at every step:

- We accept pre-submission inquiries

- Our selector tool helps you to find the most relevant journal

- We provide round the clock customer support

- Convenient online submission

- Thorough peer review

- Inclusion in PubMed and all major indexing services

- Maximum visibility for your research

Submit your manuscript at www.biomedcentral.com/submit
Biomed Central 